University of Wollongong

Research Online

Faculty of Engineering and Information

Faculty of Engineering and Information

Sciences - Papers: Part A

Sciences

$1-1-2014$

Co-digestion of sewage sludge and crude glycerol for on-demand biogas production

Long Nghiem

University of Wollongong, longn@uow.edu.au

Thanh Nguyen

University of Wollongong, ttn067@uowmail.edu.au

Patric Manassa

University of Wollongong, patrie@uow.edu.au

Shona K. Fitzgerald

Sydney Water Corporation

Marcia Dawson

Sydney Water Corporation

See next page for additional authors

Follow this and additional works at: https://ro.uow.edu.au/eispapers

Part of the Engineering Commons, and the Science and Technology Studies Commons

Research Online is the open access institutional repository for the University of Wollongong. For further information contact the UOW Library: research-pubs@uow.edu.au 


\title{
Co-digestion of sewage sludge and crude glycerol for on-demand biogas production
}

\begin{abstract}
Pilot scale experiments, biomethane potential (BMP) evaluation, and BioWin simulations were conducted to evaluate the intermittent co-digestion of sewage sludge and crude glycerol for on-demand biogas production. BMP tests revealed that both pure and crude glycerols were readily biodegradable. BioWin simulations showed that intermittent glycerol injection at a high $(3 \% \mathrm{v} / \mathrm{v})$ dose might lead to an increase in chemical oxygen demand of the digestate. Results from the pilot scale experiments confirmed that intermittent injection of crude glycerol at both low $(0.63 \% \mathrm{v} / \mathrm{v})$ and high $(3 \% \mathrm{v} / \mathrm{v})$ doses could be used for on-demand biogas production to match the daily fluctuation in energy consumption at a typical wastewater treatment plant. However, in terms of additional biogas production per volume of added glycerol, the lower dose $(0.63 \% \mathrm{v} / \mathrm{v})$ was more effective. The additional methane yield (at the glycerol dose of $0.63 \% \mathrm{v} / \mathrm{v}$ ) was $1.3 \mathrm{~m} 3$ per litre of crude glycerol. This value obtained from the pilot scale experiment was higher than that from the BMP test but lower compared to that predicted from the BioWin simulation.
\end{abstract}

\section{Keywords}

sludge, sewage, production, digestion, biogas, co, demand, glycerol, crude

Disciplines

Engineering | Science and Technology Studies

\section{Publication Details}

Nghiem, L. D., Nguyen, T. T., Manassa, P., Fitzgerald, S. K., Dawson, M. \& Vierboom, S. (2014). Co-digestion of sewage sludge and crude glycerol for on-demand biogas production. International Biodeterioration and Biodegradation, 95, Part A, 160-166.

\section{Authors}

Long Nghiem, Thanh Nguyen, Patric Manassa, Shona K. Fitzgerald, Marcia Dawson, and Sarah Vierboom 


\title{
Co-digestion of sewage sludge and crude glycerol for on-demand biogas production
}

Revised Manuscript Submitted to

\section{International Biodeterioration and Biodegradation}

\author{
April 2014 \\ Long D. Nghiem ${ }^{\mathrm{a}, *}$, Thanh T. Nguyen ${ }^{\mathrm{a}}$, Patrick Manassa ${ }^{\mathrm{a}}$, Shona K. Fitzgerald ${ }^{\mathrm{b}}$, Marcia \\ Dawson $^{\mathrm{b}}$, and Sarah Vierboom ${ }^{\mathrm{b}}$ \\ ${ }^{a}$ Strategic Water Infrastructure Laboratory, School of Civil Mining and Environmental \\ Engineering, University of Wollongong, Wollongong, NSW 2522, Australia \\ ${ }^{\mathrm{b}}$ Sydney Water Corporation, Parramatta, NSW 2124, Australia
}

\footnotetext{
* Corresponding author: Long Duc Nghiem, Email: longn@uow.edu.au; Ph +61 242214590
} 


\section{Abstract}

Pilot scale experiments, biomethane potential (BMP) evaluation, and BioWin simulations were conducted to evaluate the intermittent co-digestion of sewage sludge and crude glycerol for on-demand biogas production. BMP tests revealed that both pure and crude glycerols were readily biodegradable. BioWin simulations showed that intermittent glycerol injection at a high $(3 \% \mathrm{v} / \mathrm{v})$ dose might lead to an increase in chemical oxygen demand of the digestate. Results from the pilot scale experiments confirmed that intermittent injection of crude glycerol at both a low $(0.63 \% \mathrm{v} / \mathrm{v})$ and a high $(3 \% \mathrm{v} / \mathrm{v})$ doses could be used to for on-demand biogas production to match the daily fluctuation in energy consumption at a typical wastewater treatment plant. However, in terms of additional biogas production per volume of added glycerol, the lower dose $(0.63 \% \mathrm{v} / \mathrm{v})$ was more effective. The additional methane yield (at the glycerol dose of $0.63 \% \mathrm{v} / \mathrm{v}$ ) was $1.3 \mathrm{~m}^{3}$ per litre of crude glycerol. This value obtained from the pilot scale experiment was higher than that from the BMP test but lower compared to that predicted from the BioWin simulation.

Keywords: Sewage sludge, crude glycerol, anaerobic co-digestion, biomethane potential, ondemand biogas production, BioWin simulation.

\section{Introduction}

Anaerobic digestion is a process where microorganisms break down organic materials such as food scraps and manure, in the absence of oxygen, into biogas and biosolids. Biogas is a renewable source of energy, while biosolids are a valuable fertiliser and soil conditioner. Anaerobic digestion plays a vital role for stabilising sewage sludge from municipal wastewater treatment for beneficial reuse or environmental disposal (Park et al., 2006; Yoshida et al., 2013).

In a typical wastewater treatment plant (WWTP), a significant amount of solid material is collected from the settling (i.e. primary treatment) and activated sludge (i.e. secondary treatment) processes. These are collectively called sewage sludge and must be treated prior to disposal for environmental protection. Sludge management can account for up to $60 \%$ of the total cost associated with municipal wastewater treatment (Ramakrishna \& Viraraghavan, 2005). As a result, significant effort has been devoted toward minimising sludge generation (Semblante et al., 2014) and optimising sludge treatment (Brisolara \& Qi, 2011; Wang et al., 
2008). Among several options currently available for sewage sludge treatment, anaerobic digestion is probably the most widely used technology.

Until recently little attention was given to the production of biogas production by anaerobic digestion (Barber, 2012). Nevertheless, growing concerns about energy security, environmental impacts and increasing energy cost for wastewater treatment have re-instated the anaerobic digestion process as a major renewable energy production technology to the centre of the scientific spotlight (Iacovidou et al., 2012; Jenicek et al., 2013; Karthikeyan \& Visvanathan, 2013; Khanal et al., 2008). In particular, using anaerobic digestion to co-digest sewage sludge with other organic waste materials to enhance both biogas production and the quality of the treated biosolids has been proposed and implemented at several WWTPs around the world (Athanasoulia et al., 2014; Cabbai et al., 2013; Pitk et al., 2013; Ratanatamskul et al., 2011; Wang et al., 2013). This can be achieved by using existing anaerobic digestion infrastructure at WWTPs without any significant capital investment.

Glycerol is a notable co-substrate that has received significant scientific and commercial attention in recent years (Athanasoulia et al., 2014; Fountoulakis et al., 2010; Leoneti et al., 2012). Crude glycerol is an organic by-product generated from biodiesel production and accounts for about $10 \%$ of the total product stream in volume (Santibáñez et al., 2011). Biodiesel can be produced from renewable feed stocks such as vegetable oil, waste cooking oils and animal fats and as such it is a viable alternative to diesel fuel. Over the last few years, the production of biodiesel has experienced an exponential increase. As a result, there has been a considerable build-up of crude glycerol surplus (Gupta \& Kumar, 2012). Inappropriate disposal of glycerol can have severe environmental consequences. It is also expensive to purify crude glycerol for reuse. Therefore, the management of crude glycerol can be a major bottle neck to the biodiesel industry (Leoneti et al., 2012). However, crude glycerol can be an ideal organic substrate for co-digestion with the sewage sludge as it can be easily handled and stored over a long period of time (Fountoulakis et al., 2010; Leoneti et al., 2012; Razaviarani et al., 2013).

Despite the potential value of crude glycerol as a co-substrate in anaerobic digestion to increase biogas production, it has only recently been studied, mostly at laboratory scale levels. Fountoulakis et al., (2010) used a laboratory scale digester of $1 \mathrm{~L}$ in active volume to conduct co-digestion experiments between glycerol and wastewater sludge. They reported that glycerol addition of $1 \%(\mathrm{v} / \mathrm{v})$ concentration to the feed can boost biogas yields (Fountoulakis 
et al., 2010). However, 3\% (v/v) glycerol addition could destabilise the system, thus ceasing the anaerobic digestion process (Fountoulakis et al., 2010). In a recent pilot study conducted at the Gold Bar WWTP in Alberta (Canada), Razaviarani et al., (2013) reported that glycerol addition to wastewater sludge at $1.1 \%(\mathrm{v} / \mathrm{v})$ does not only increase biogas production but also improves the removal of chemical oxygen demand (COD) and volatile solids (VS). Razaviarani et al., (2013) also showed that prolonged glycerol addition at 1.8\% (v/v) was detrimental to the anaerobic digestion process.

An interesting aspect that had not been investigated was intermittent glycerol addition to boost the production of biogas during peak periods of energy consumption. Most wastewater treatment plants do not have extensive gas storage facilities to ensure energy demands can be matched at all times by biogas cogeneration. A recent energy review conducted at a WWTP in Sydney (Australia) showed that cogeneration at the plant achieved more than $80 \%$ energy self-sufficiency for approximately 18 hours of the day, but during periods of peak energy consumption only produced 50\% of the plant's energy needs. Thus, the use of glycerol addition to increase biogas production at the time of need will provide further economic savings and environmental benefits. This study aims to evaluate the intermittent addition of crude glycerol to sewage sludge for on-demand biogas production.

\section{Materials and methods}

\subsection{Wastewater sludge and glycerol}

Raw primary sludge was obtained from a full scale sewage treatment plant. Digested sludge (digestate) from the same plant was used as innoculum for the biomethane potential and pilot experiments. Analytical grade glycerol (purity > 99\%) was obtained from VWR International (Australia). Crude glycerol was obtained from a biodiesel production facility in Australia and was used without any further purification.

\subsection{Biomethane potential experimental protocol}

Biomethane potential (BMP) of crude and pure glycerols was measured using customised equipment consisting of fermentation bottles submerged in a water bath and a biogas collection gallery (Figure 1). The fermentation bottle (Wiltronics Research Pty Ltd) was made of glass. Each bottle (1000 mL) was equipped with a rubber bung with an S-shape air-lock and was connected to a plastic valve and a gas collector through flexible plastic tube. The air- 
lock is filled with water to allow biogas to escape, but prevents air from entering the fermentation bottle. The bottle was submerged in the water bath (Model SWB20D, Ratek Instrument Pty Ltd) to maintain the temperature at $35.0 \pm 0.1^{\circ} \mathrm{C}$. The gas collector comprised a $1000 \mathrm{~mL}$ plastic measuring cylinder and a plastic container containing $\mathrm{NaOH}(1 \mathrm{M})$.

\section{[Figure 1]}

Prior to the BMP experiment, all fermentation bottles were flushed with pure $\mathrm{N}_{2}$ for 5 minutes before filling with $750 \mathrm{~mL}$ of substrate. The substrate consisted of digestate from a full scale plant (which was used as the innoculum) and glycerol. A set of BMP experiments using digestate as the only substrate was also conducted as a reference. The bottle was flushed again with $\mathrm{N}_{2}$ and immediately sealed with the rubber bung. After placing the bottle into the shaking water bath, the valve was opened to allow biogas to enter the gas collection gallery. To measure the volume of $\mathrm{CH}_{4}$ generated from the fermentation bottle, the cylinder was first filled with $1 \mathrm{M} \mathrm{NaOH}$ solution, and was inverted and then partially submerged into the $\mathrm{NaOH}$ container. Biogas from the fermentation bottle was introduced into the submerged part of the cylinder, thus allowing the $\mathrm{NaOH}$ solution to absorb $\mathrm{CO}_{2}$ and $\mathrm{H}_{2} \mathrm{~S}$ from the biogas. The remaining $\mathrm{CH}_{4}$ gas displaced the $\mathrm{NaOH}$ solution inside cylinder and the $\mathrm{CH}_{4}$ gas volume generated was recorded daily. The experiment was terminated when less than $5 \mathrm{~mL}$ /day of $\mathrm{CH}_{4}$ was produced. All BMP experiments were conducted in duplicate.

\subsection{Pilot anaerobic digester}

A pilot anaerobic digestion system consisting of a single stage $50 \mathrm{~L}$ continuously stirred tank reactor was used (Figure 2). The system was equipped with a Supervisory Control and Data Acquisition unit. The digester was maintained at $35.0 \pm 0.1{ }^{\circ} \mathrm{C}$ and was inoculated with digested sludge taken from a full scale anaerobic digester treating primary sewage sludge. Primary sludge from the WWTP was fed into the feeding hopper at least twice a week. A peristaltic pump then transferred $104 \mathrm{~mL}$ of sludge into the digester every hour on a semicontinuous basis, resulting in a hydraulic retention time (HRT) of 20 days. The digester has an injection port equipped with a non-return valve for dosing liquid substrates into the reactor. The pilot anaerobic digester had been continuously operated for several months before this study. Prior to the addition of glycerol as a co-substrate, the digestion process was operated for one month until a stable biogas flow rate was achieved. This provided a baseline gas flow from which the extra biogas generated by glycerol could be compared. 


\subsection{Experimental protocol}

Continuous addition of glycerol to sewage sludge at high concentration can be detrimental to the anaerobic digestion process. Razaviarani et al., (2013) reported that prolonged glycerol addition at $1.8 \%(\mathrm{v} / \mathrm{v})$ could destabilise anaerobic digestion. In a previous study, we observed that more than a week of continuous glycerol addition at 3\% (v/v) to primary sludge could lead to a severe deterioration in performance of the digester with respect to biogas production and COD or VS destruction (data not shown). Thus, in this study, two glycerol doses of 0.63 and 3.0\% (v/v) were investigated using the pilot anaerobic digester. The former represents a dose at which continuous glycerol addition to sewage sludge could be used without any negative effects on anaerobic digestion. The letter represents a high dose at which, continuous glycerol addition could jeopardise anaerobic digestion. For each experiment the addition was conducted as a discrete injection every hour to obtain an equivalent glycerol addition of 0.63 or 3.0\% (v/v) over a 6 hour period. A syringe was used to inject the required volume of glycerol diluted in $20 \mathrm{~mL}$ of water.

\subsection{Analytical methods}

COD of the glycerol was measured using a Hach DBR200 COD Reactor and a Hach DR/2000 spectrophotometer (program number 435 COD HR) following the US-EPA standard method Standard Method 5220 D. Cationic content of the crude glycerol was determined by diluting glycerol with Milli-Q water by 10 times. The obtained samples were analysed using an Agilent 7500cs ICP-MS. A Merck ICP multi-element standard solution was used for calibration. The details of this analytical method are available elsewhere (Tu et al., 2013). Total COD (denoted as $\mathrm{COD}_{\mathrm{t}}$ ) of the raw primary and digestate was measured using the same protocol as that of glycerol. Soluble COD (denoted as $\mathrm{COD}_{\mathrm{s}}$ ) was determined by first filtering the sludge sample using a Millipore HA membrane with pore size of $0.45 \mu \mathrm{m}$ to obtain the fitrate for subsequent COD analysis as above. Total solids (TS), VS, and pH of the raw primary sludge and digestate were measured within two days after collection according to the standard methods (Eaton et al., 2005). All samples were kept at $4{ }^{\circ} \mathrm{C}$ to avoid any further biological activity. Alkalinity of the digestate was also measured according to the standard methods (Eaton et al., 2005). Biogas composition was measured using a portable biogas meter (Biogas 5000, Geotech UK). The volume of additional biogas produced due to the addition of 
glycerol was calculated by integrating the gas flow rate during the period of the experiment over the biogas production baseline.

\subsection{BioWin simulation}

A BioWin model (BioWin 3.1, EnviroSim Associates Ltd, Ontario, Canada) was set up to simulate the performance of a single stage mesophilic $\left(35^{\circ} \mathrm{C}\right)$ anaerobic digester (Figure 3 ). Average values of COD, total Kjehldahl nitrogen (TKN), total phosphorus (TP), alkalinity and $\mathrm{pH}$ of the raw primary sludge obtained from the full scale sewage treatment plant were used as input parameters (Table 1). The digester HRT was set at 20 days (which was the value used during the pilot experiment). Glycerol addition was simulated as a separate influent input to the digester. The glycerol flow rate was $0.63 \%$ or $3 \%(\mathrm{v} / \mathrm{v})$ compared to the primary sludge flow rate. The primary sludge flow rate was constant while the additional glycerol flow was over six hours from 7 am to $1 \mathrm{pm}$. Because BioWin does not have a specific function for simulating glycerol as a co-substrate, in this study, the added COD from glycerol was simulated as either 'readily biodegradable COD (from complex substrate)' or 'COD from methanol'. Both methanol and a readily biodegradable 'complex' substrate can be completely degraded. However, the difference between these two scenarios is in the biodegradation rate. The biodegradation rate of methanol is faster than that of a readily biodegradable 'complex' substrate.

[Figure 3]

\section{[Table 1]}

\section{Results and discussion}

\subsection{Glycerol characterisation}

According to the supplier, the crude glycerol used in this study has about 50\% purity. The remaining is known as matter organic non-glycerol (or MONG). MONG is essentially fatty acids in the form of sodium and potassium soaps with a small amount of methanol (Hansen et al., 2009). Despite the significant difference in the level of purity, crude and pure glycerols have a similar COD content of approximately $1 \mathrm{~kg} / \mathrm{L}$ (Table 2). The boiling point of crude glycerol is considerably lower than that of pure glycerol. 
In addition to the organic impurity, crude glycerol used in this study contained approximately $17 \mathrm{~g} / \mathrm{L}$ of sodium and a small amount of potassium (Table 2). These are alkali metals from the catalysts used during biodiesel production. Sodium concentration is of interest for anaerobic co-digestion as concentrations of $3 \mathrm{~g} / \mathrm{L}$ or greater are toxic to methanogenic bacteria (Feijoo et al., 1995). High sodium concentrations in crude glycerol could cause salt toxicity if the raw wastewater sludge also has a high salinity content or if excessive crude glycerol ( $>18 \% \mathrm{v} / \mathrm{v})$ is added to the digester.

\section{[Table 2]}

\subsection{Biomethane potential of crude and pure glycerols}

Methane production from crude and pure glycerols was measured using the BMP equipment by adding glycerol $(0.25 \%$ and $0.5 \%, v / v)$ to the digestate. Glycerol doses higher than $0.5 \%$ (v/v) were not investigated using the BMP equipment. Dosing higher than $1 \% \mathrm{v} / \mathrm{v}$ glycerol can result in the accumulation of volatile fatty acid in the fermentation bottles, which can destabilise BMP experiments (data not shown). The methane production attributed to glycerol was calculated by subtracting the volume produced by the digestate in the 'control', which was approximately 1,250 mL (Figure 4), as described in section 2.3. It is also noteworthy that, in this study, the experimental errors between two replicate BMP tests were always less than 3\% (Figure 4). As expected, the addition of $0.5 \%(\mathrm{v} / \mathrm{v})$ glycerol resulted in a higher total methane production than when $0.25 \%(\mathrm{v} / \mathrm{v})$ of glycerol was added. However, at the lower dose of $0.25 \%(\mathrm{v} / \mathrm{v})$, the specific methane production (volume of methane produced per litre of added COD) was $0.67 \mathrm{~m}^{3} / \mathrm{L}$ glycerol. On the other hand, at the higher dose of $0.5 \%(\mathrm{v} / \mathrm{v})$, the specific methane production was only $0.33 \mathrm{~m}^{3} / \mathrm{L}$ glycerol.

At the higher dose of $0.5 \%(\mathrm{v} / \mathrm{v})$, a higher volume of methane can be produced from pure glycerol compared to crude glycerol. A similar observation was made at the lower dose of $0.25 \%$ for the first 10 days. However, there was then a gradual increase in the methane production from crude glycerol. By the end of the experimental period (after 30 days) methane production from both the crude and pure glycerol was almost identical.

The higher initial methane production from the pure glycerol could be attributed to the higher level of purity compared to the crude glycerol. It is noteworthy that methane production occurred immediately at the beginning of the BMP experiments when the lower dose of $0.25 \%(\mathrm{v} / \mathrm{v})$ of glycerol was used (Figure 5$)$. When the higher dose of $0.5 \%(\mathrm{v} / \mathrm{v})$ of glycerol 
was used, there appears to be a lag time of up to 4 days before significant methane production was observed (Figure 5). The reason for this lag time at high glycerol dose is not clear but could be attributed to COD shock loading within the BMP test bottle. Nevertheless, in all cases, most of the methane production from glycerol occurred within the first $7-8$ days of the BMP experiments (Figure 5). The results suggest that the organic impurity in crude glycerol is also readily biodegradable and thus it can be used as a co-substrate to enhance methane production without any negative impact on the COD content of the digestate.

\section{[Figure 4]}

\section{[Figure 5]}

\subsection{BioWin simulation}

The simulated increase in biogas flow rates due to glycerol addition from 7 am to $1 \mathrm{pm}$ at 0.63\% and 3\% (v/v) are shown in Figure 6. Significantly higher biogas flow rate was obtained when glycerol addition was simulated as methanol rather than readily biodegradable complex substrate. When glycerol addition was simulated as methanol at $0.63 \%$ or $3 \%(\mathrm{v} / \mathrm{v})$, the increase in biogas production occurred instantaneously and it took only about 3 hours for biogas production to return to the baseline value once glycerol addition had ceased. When glycerol addition was simulated as a readily biodegradable complex substrate, the increase in biogas flow rate was much smaller. At $0.63 \%$ (v/v) glycerol addition, the biogas flow rate returned to the baseline value at midnight (i.e. 11 hours after glycerol addition has ceased) while at 3\% (v/v) glycerol addition, the biogas flow rate could only return to the baseline value after more than 30 hours since glycerol addition has ceased).

\section{[Figure 6]}

The increase in biogas production could be calculated by integrating the additional flow rate over the baseline using trapezoidal rule over the 6 hours of glycerol injection. The $0.63 \%$ and $3 \%(\mathrm{v} / \mathrm{v})$ glycerol addition resulted in $16 \%$ and $81 \%$ increase in biogas production if glycerol behaves like methanol or $9 \%$ and 58\% if glycerol behaves like a readily biodegradable complex substrate, respectively. This corresponds to $9.4 \mathrm{~m}^{3}$ to $10 \mathrm{~m}^{3}$ of biogas/L of added glycerol that behaves like methanol or $5.4 \mathrm{~m}^{3}$ to $7.2 \mathrm{~m}^{3}$ of biogas/L of added glycerol that behaves like a readily biodegradable complex substrate. 
It is noteworthy that the biogas composition obtained from all 4 scenarios simulated here was consistent (i.e. $62 \% \mathrm{CH}_{4}$ and $38 \% \mathrm{CO}_{2}$ ). When glycerol addition was simulated at $3 \%(\mathrm{v} / \mathrm{v})$ as a readily biodegradable complex substrate, an increase in the digestate COD from 25,000 $\mathrm{mg} / \mathrm{L}$ to $27,000 \mathrm{mg} / \mathrm{L}$ by the end of the simulated day. In all other scenarios, the digestate COD did not increase during or after glycerol addition. Results from this simulation exercise suggest that the simple and readily biodegradable substrate can be used to generate ondemand biogas to match daily energy demand patterns without any negative impact on the digestate quality. An additional benefit is that intermittent dosing would limit the volume of glycerol added to the system to hence avoid operational instability due to an increase in the COD of the digestate.

\subsection{On demand biogas production using a pilot anaerobic digester}

Composition of the biogas obtained from the pilot experiments before and after crude glycerol injection remained the same, with methane content of 55-60\% (Table 3). Samples of digestate from the pilot anaerobic digester show that the COD of the digestate was not affected by the addition of crude glycerol. Also, the high alkalinity of the digestate, above $2000 \mathrm{mg} / \mathrm{L}$ (as $\mathrm{CaCO}_{3}$ ), suggests that the digester remained in a stable condition (Table 3).

\section{[Table 3]}

The biogas flow rates, as a function of time, when crude glycerol was injected to the pilot digester are shown in Figure 7. The increase in biogas production was almost immediate following glycerol injection (Figure 7). The highest biogas flow rate was observed 4-5 hours after the first injection. Similarly, the biogas flow returned to the baseline value 4-5 hours after the last injection. There were some gradual fluctuations in the baseline biogas flow rate (without any glycerol addition) possibly due to variation in the COD content of the raw sludge. Nevertheless, the baseline over the day of glycerol addition can be considered as stable. When $0.63 \%$ of crude glycerol was added to the digester, the maximum biogas flow rate was about $50 \%$ higher than the baseline value. When $3 \%$ of crude glycerol was added to the digester, the maximum biogas flow rate was about $80 \%$ higher than the baseline value. In addition, there appears to be a shift in the baseline biogas flow rate after the conclusion of crude glycerol injection. The data does not conclusively show that a shift in the baseline biogas flow rate can occur with a high crude glycerol dose of 3\% (v/v). Nevertheless, it highlights the unstable nature of injecting glycerol at a high concentration (Fountoulakis et 
al., 2010; Razaviarani et al., 2013). Although the anaerobic system may be able to recover when a high dose of crude glycerol is intermittently injected into the digester, the injected glycerol may not be fully degraded, resulting in a lower biogas production per volume of added glycerol.

The biogas yield due to $0.63 \%$ crude glycerol addition was $1.3 \mathrm{~m}^{3} / \mathrm{L}$ of glycerol (from both replicates). This was about 2 times higher than the value obtained from the BMP test (section 3.2), but was 2 times lower than the value obtained from BioWin modelling when glycerol addition was simulated as readily biodegradable complex substrate. In comparison, the biogas yield due to $3 \%$ crude glycerol addition was significantly lower $\left(0.65 \mathrm{~m}^{3} / \mathrm{L}\right.$ of glycerol). The pilot results reported here suggest that lower dose (0.63\%) of glycerol addition may be more cost-effective than a higher dose (3\%).

\section{[Figure 7]}

\section{Conclusion}

This study demonstrated the intermittent injection of crude glycerol to sewage sludge for ondemand biogas production by anaerobic digestion through a series of laboratory scale experiments, computer simulation, and pilot scale validation. Laboratory scale results showed that both pure and crude glycerols are readily biodegradable. Computer simulation using BioWin showed that it is possible to match the daily variation in energy demand by intermittent glycerol injection. Pilot scale data confirmed the feasibility of intermittent crude glycerol injection for on-demand biogas production. In terms of additional biogas production per volume of added glycerol, the lower dose $(0.63 \% \mathrm{v} / \mathrm{v})$ was more effective. The additional methane yield (at the glycerol dose of $0.63 \% \mathrm{v} / \mathrm{v}$ ) obtained from the pilot scale experiment was $1.3 \mathrm{~m}^{3}$ per litre of crude glycerol. This value was higher than that from the BMP test but lower compared to that predicted from the BioWin simulation.

\section{Acknowledgement}

The West Ryde Laboratory (Sydney Water Corporation) is thanked for their assistance with primary sludge and digestate analysis. 


\section{References}

Athanasoulia, E., Melidis, P., Aivasidis, A. 2014. Co-digestion of sewage sludge and crude glycerol from biodiesel production. Renewable Energy, 62, 73-78.

Barber, W.P.F. 2012. Influence of changing drivers on realising the value of sewage sludge as a resource. Water Practice and Technology, 7(4).

Brisolara, K.F., Qi, Y. 2011. Biosolids and sludge management. Water Environment Research, 83(10), 1351-1375.

Cabbai, V., Ballico, M., Aneggi, E., Goi, D. 2013. BMP tests of source selected OFMSW to evaluate anaerobic codigestion with sewage sludge. Waste Management, 33(7), 1626-1632.

Eaton, A.D., Clesceri, L.S., Greenberg, A.E. 2005. Standard Methods for Examination of Water \& Wastewater 21st ed. American Public Health Association

Feijoo, G., Soto, M., Méndez, R., Lema, J.M. 1995. Sodium inhibition in the anaerobic digestion process: Antagonism and adaptation phenomena. Enzyme and Microbial Technology, 17(2), 180-188.

Fountoulakis, M.S., Petousi, I., Manios, T. 2010. Co-digestion of sewage sludge with glycerol to boost biogas production. Waste Management, 30(10), 1849-1853.

Gupta, M., Kumar, N. 2012. Scope and opportunities of using glycerol as an energy source. Renewable and Sustainable Energy Reviews, 16(7), 4551-4556.

Hansen, C.F., Hernandez, A., Mullan, B.P., Moore, K., Trezona-Murray, M., King, R.H., Pluske, J.R. 2009. A chemical analysis of samples of crude glycerol from the production of biodiesel in Australia, and the effects of feeding crude glycerol to growing-finishing pigs on performance, plasma metabolites and meat quality at slaughter. Animal Production Science, 49(2), 154-161.

Iacovidou, E., Ohandja, D.G., Voulvoulis, N. 2012. Food waste co-digestion with sewage sludge - Realising its potential in the UK. Journal of Environmental Management, 112, 267274.

Jenicek, P., Kutil, J., Benes, O., Todt, V., Zabranska, J., Dohanyos, M. 2013. Energy selfsufficient sewage wastewater treatment plants: Is optimized anaerobic sludge digestion the key? Water Science and Technology, 68(8), 1739-1743. 
Karthikeyan, O.P., Visvanathan, C. 2013. Bio-energy recovery from high-solid organic substrates by dry anaerobic bio-conversion processes: A review. Reviews in Environmental Science and Biotechnology, 12(3), 257-284.

Khanal, S.K., Rasmussen, M., Shrestha, P., Van Leeuwen, H.J., Visvanathan, C., Liu, H. 2008. Bioenergy and Biofuel Production from Wastes/Residues of Emerging Biofuel Industries. Water Environment Research, 80(10), 1625-1647.

Leoneti, A.B., Aragão-Leoneti, V., de Oliveira, S.V.W.B. 2012. Glycerol as a by-product of biodiesel production in Brazil: Alternatives for the use of unrefined glycerol. Renewable Energy, 45, 138-145.

Park, C., Abu-Orf, M.M., Novak, J.T. 2006. The digestibility of waste activated sludges. Water Environment Research, 78(1), 59-68.

Pitk, P., Kaparaju, P., Palatsi, J., Affes, R., Vilu, R. 2013. Co-digestion of sewage sludge and sterilized solid slaughterhouse waste: Methane production efficiency and process limitations. Bioresource Technology, 134, 227-232.

Ramakrishna, D.M., Viraraghavan, T. 2005. Strategies for sludge minimization in activated sludge process - A review. Fresenius Environmental Bulletin, 14(1), 2-12.

Ratanatamskul, C., Wattanayommanaporn, O., Yamamoto, K. 2011. Codigestion of food waste and sewage sludge by two stage anaerobic digester for biogas production from high rise building. Thirteenth International Waste Management and Landfill Symposium, Cagliari, Italy. CISA Publisher.

Razaviarani, V., Buchanan, I.D., Malik, S., Katalambula, H. 2013. Pilot scale anaerobic codigestion of municipal wastewater sludge with biodiesel waste glycerin. Bioresource Technology, 133, 206-212.

Santibáñez, C., Varnero, M.T., Bustamante, M. 2011. Residual glycerol from biodiesel Manufacturing, waste or potential source of Bioenergy: A review. Chilean Journal of Agricultural Research, 71(3), 469-475.

Semblante, S., Hai, F.I., Guo, W.S., Ngo, H.H., You, S.-J., Price, W., Nghiem, D.L. 2014. Sludge cycling between aerobic, anoxic and anaerobic regimes to reduce sludge production during wastewater treatment: performance, mechanisms, and implications. Bioresource Technology, Accepted 8 Jan 2014. 
Tu, K.L., Chivas, A.R., Nghiem, L.D. 2013. Enhanced boron rejection by NF/RO membranes by complexation with polyols: Measurement and mechanisms. Desalination, 310, 115-121.

Wang, H., Brown, S.L., Magesan, G.N., Slade, A.H., Quintern, M., Clinton, P.W., Payn, T.W. 2008. Technological options for the management of biosolids. Environmental Science and Pollution Research, 15(4), 308-317.

Wang, M., Sahu, A.K., Rusten, B., Park, C. 2013. Anaerobic co-digestion of microalgae Chlorella sp. and waste activated sludge. Bioresource Technology, 142, 585-590.

Yoshida, H., Christensen, T.H., Scheutz, C. 2013. Life cycle assessment of sewage sludge management: A review. Waste Management and Research, 31(11), 1083-1101. 


\title{
Co-digestion of sewage sludge and crude glycerol for on-demand biogas production
}

\section{Supplementary Data}

\author{
Submitted to
}

\section{International Biodeterioration and Biodegradation Feb 2014}

Long D. Nghiem ${ }^{\mathrm{a}, *}$, Thanh T. Nguyen ${ }^{\mathrm{a}}$, Patric Manassa ${ }^{\mathrm{a}}$, Shona K. Fitzgerald ${ }^{\mathrm{b}}$, Marcia Dawson $^{\mathrm{b}}$, and Sarah Vierboom ${ }^{\mathrm{b}}$

${ }^{\text {a }}$ Strategic Water Infrastructure Laboratory, School of Civil Mining and Environmental Engineering, University of Wollongong, Wollongong, NSW 2522, Australia

${ }^{\mathrm{b}}$ Sydney Water Corporation, Parramatta, NSW 2124, Australia

\footnotetext{
* Corresponding author: Long Duc Nghiem, Email: longn@uow.edu.au; Ph +61 242214590
} 


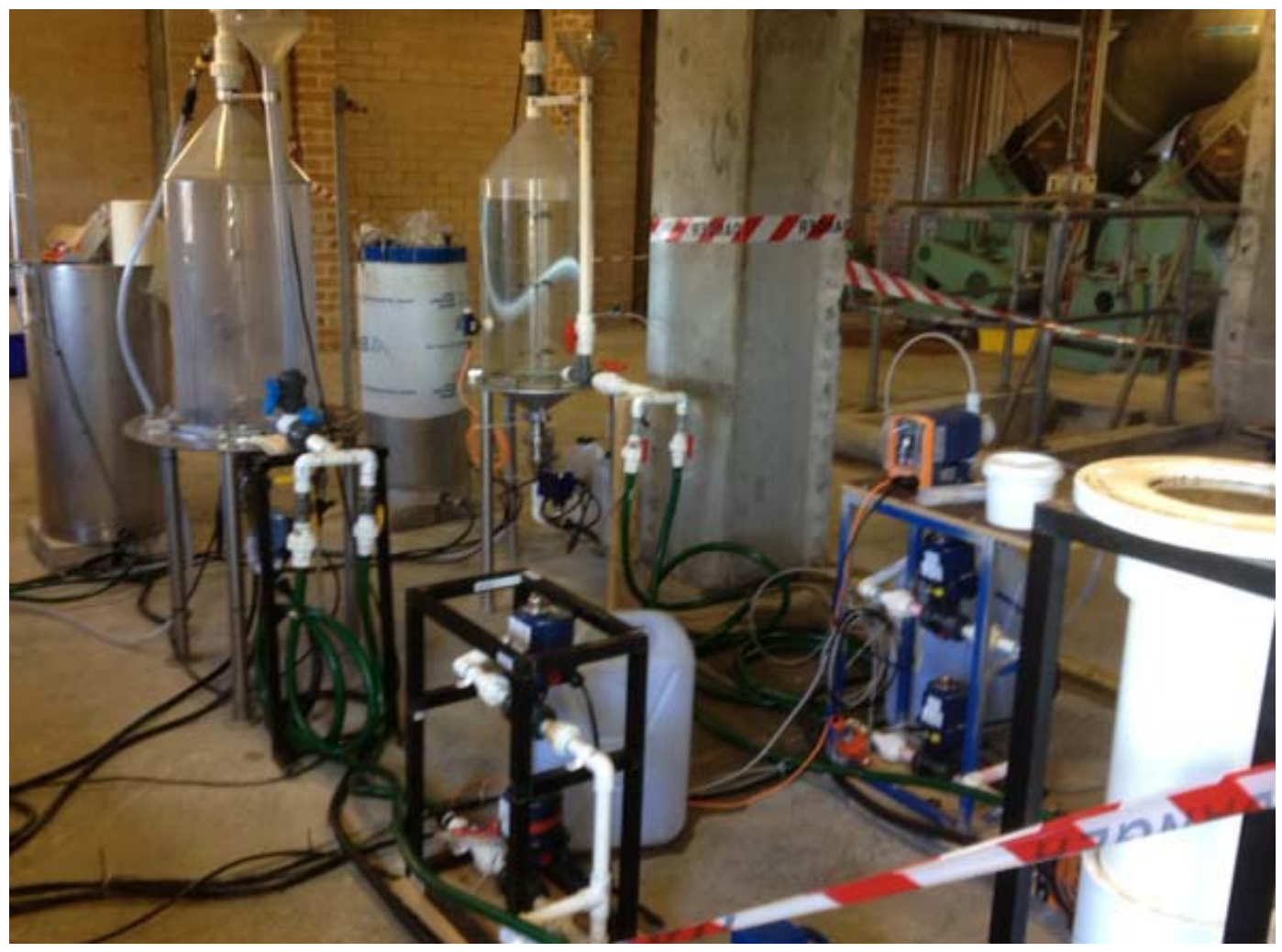

Figure S1: The pilot anaerobic digester. 


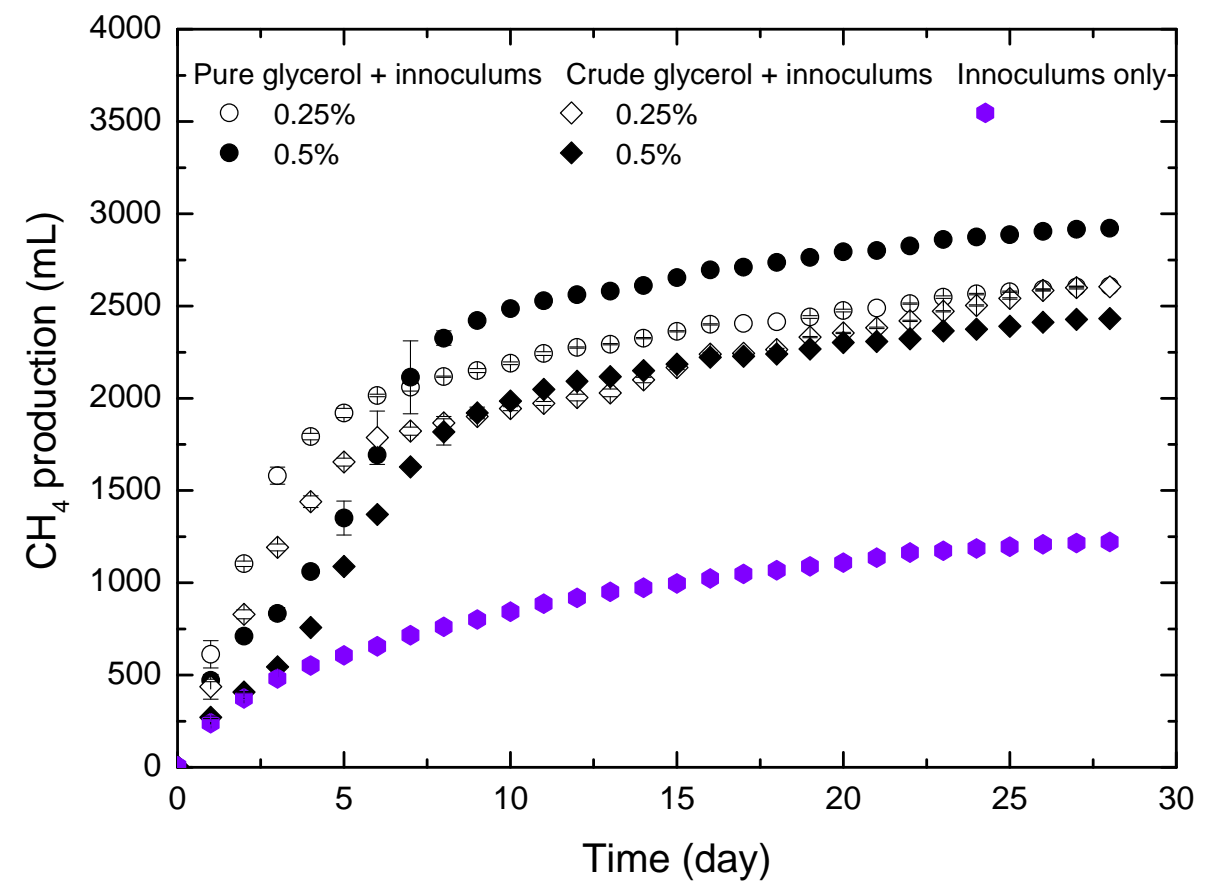

Figure S2: Methane production as a function of time from glycerol and digested sludge (inoculums) and from only digested sludge. 
381 Table 1: Input parameter of the raw primary sludge.

\begin{tabular}{|c|c|c|c|c|}
\hline $\mathrm{COD}_{\mathrm{t}}(\mathrm{mg} / \mathrm{L})$ & Alkalinity (mg/L) & TKN (mg/L) & $\mathrm{TP}(\mathrm{mg} / \mathrm{L})$ & $\mathrm{pH}$ \\
\hline 40,000 & 1,600 & 1,200 & 300 & 7.3 \\
\hline
\end{tabular}

382 Table 2: Physicochemical properties of crude and pure glycerols.

383

384

385

386

\begin{tabular}{|l|c|c|}
\hline & Crude & Pure \\
\hline Appearance & Pale brown & Clear \\
\hline pH & $8-9$ & 6.7 \\
\hline Boiling point $\left.\mathbf{(}^{\mathbf{}} \mathbf{C}\right)$ & $>130$ & 290 \\
\hline Na content (mg/L) & 16,939 & 0 \\
\hline K content (mg/L) & 454 & 0 \\
\hline Specific gravity (@ 25 $\left.{ }^{\mathbf{~}} \mathbf{C}\right)$ & 1.25 & 1.26 \\
\hline Glycerol content (\%) & $\sim 80$ & $\geq 99$ \\
\hline Matter organic non-glycerol (\%) & $<20$ & - \\
\hline COD (Kg/L) & 1.14 & 1.05 \\
\hline
\end{tabular}

Table 3: Performance of the digester during intermittent crude glycerol injection.

\begin{tabular}{|c|c|c|c|c|}
\hline \multirow{2}{*}{$\begin{array}{l}\text { Dose (v/v) } \\
\text { Replicate }\end{array}$} & \multicolumn{2}{|c|}{$0.63 \%$} & \multicolumn{2}{|c|}{$3.0 \%$} \\
\hline & $1^{\text {st }}$ & $2^{\text {nd }}$ & $1^{\text {st }}$ & $2^{\text {nd }}$ \\
\hline \multicolumn{5}{|c|}{ Digester parameters } \\
\hline Digester temperature $\left({ }^{\circ} \mathrm{C}\right)$ & 35.0 & 35.1 & 34.5 & 35.1 \\
\hline Raw sludge TS (\%) & 3.96 & 3.61 & 3.96 & 3.55 \\
\hline Digestate TS (\%) & 3.16 & 3.24 & 2.82 & 2.85 \\
\hline Raw sludge VS (\%) & 3.16 & 2.97 & 3.12 & 2.78 \\
\hline Digestate VS (\%) & 2.30 & 2.36 & 2.07 & 2.05 \\
\hline Raw sludge COD (mg/L) & 43,900 & 20,800 & 52,400 & 48,200 \\
\hline Digestate COD (mg/L) & 38,900 & 16,600 & 35,800 & 37,300 \\
\hline Digestate alkalinity (mg/L) & 2,133 & 2,105 & 2,022 & 2,047 \\
\hline \multicolumn{5}{|c|}{ Gas composition } \\
\hline $\mathrm{CH}_{4}(\%)$ & 54.1 & 58.1 & 59.4 & 59.7 \\
\hline $\mathrm{CO}_{2}(\%)$ & 29.6 & 37.1 & 39.2 & 39.9 \\
\hline
\end{tabular}



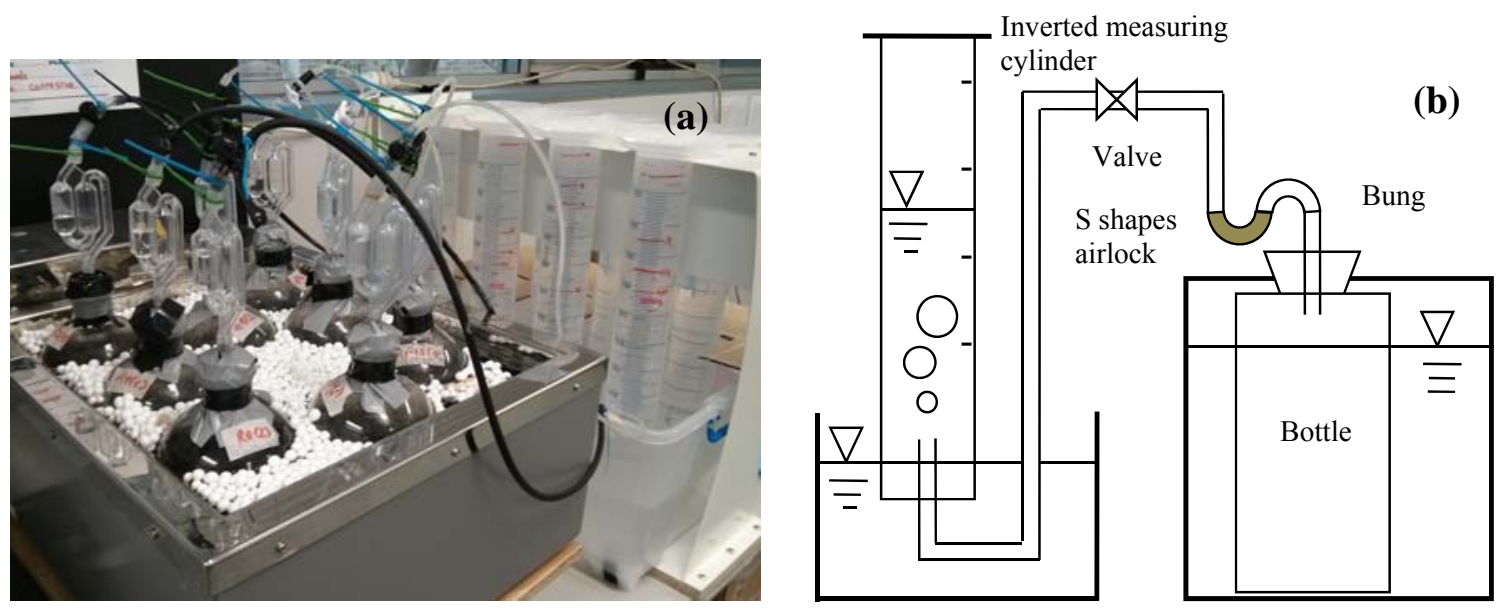

Basin contains $1 \mathrm{M} \mathrm{NaOH}$

388 Figure 1: (a) A photograph and (b) Schematic diagram of the biochemical methane potential

389 test system consisting of water bath, BMP bottles, and gas collection gallery.

390 


\section{Mixing Motor}

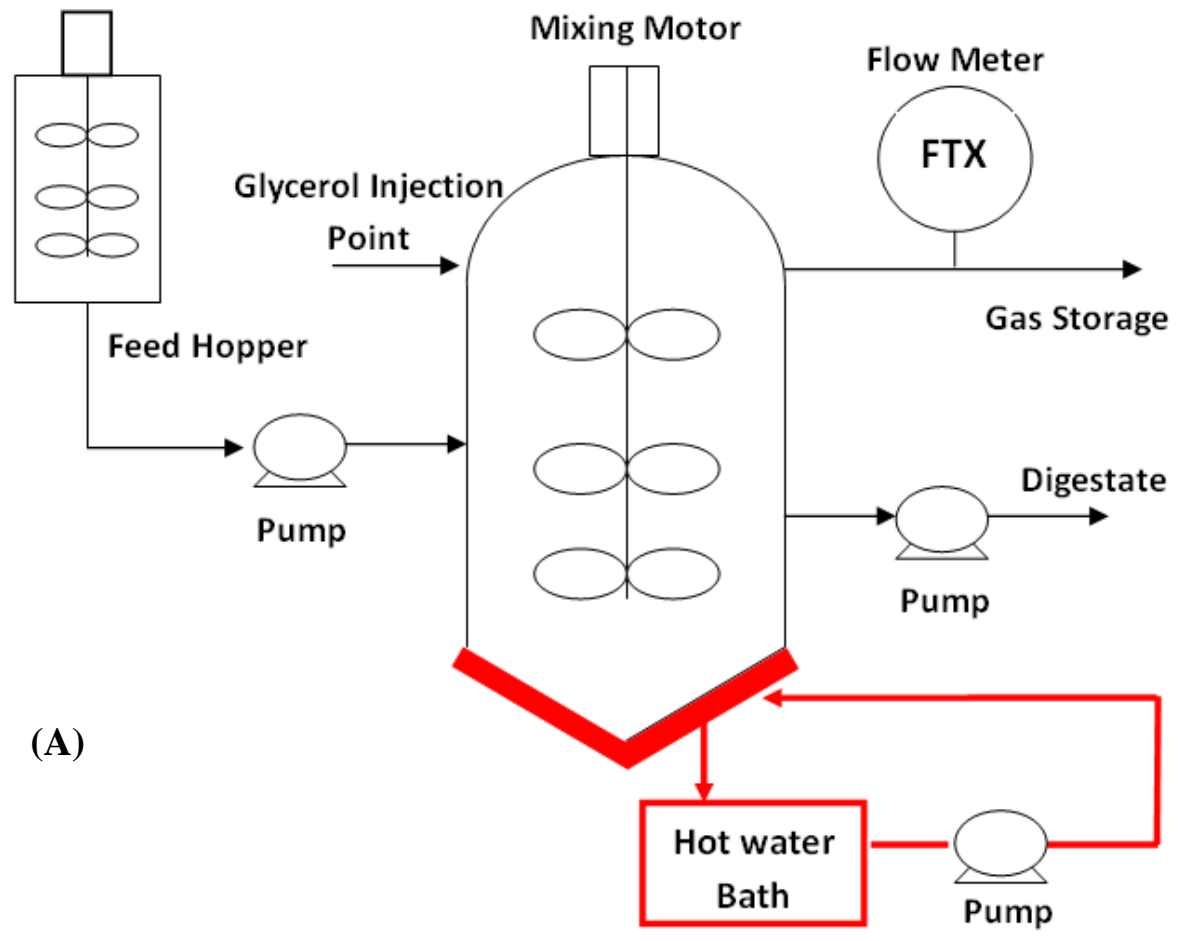

392

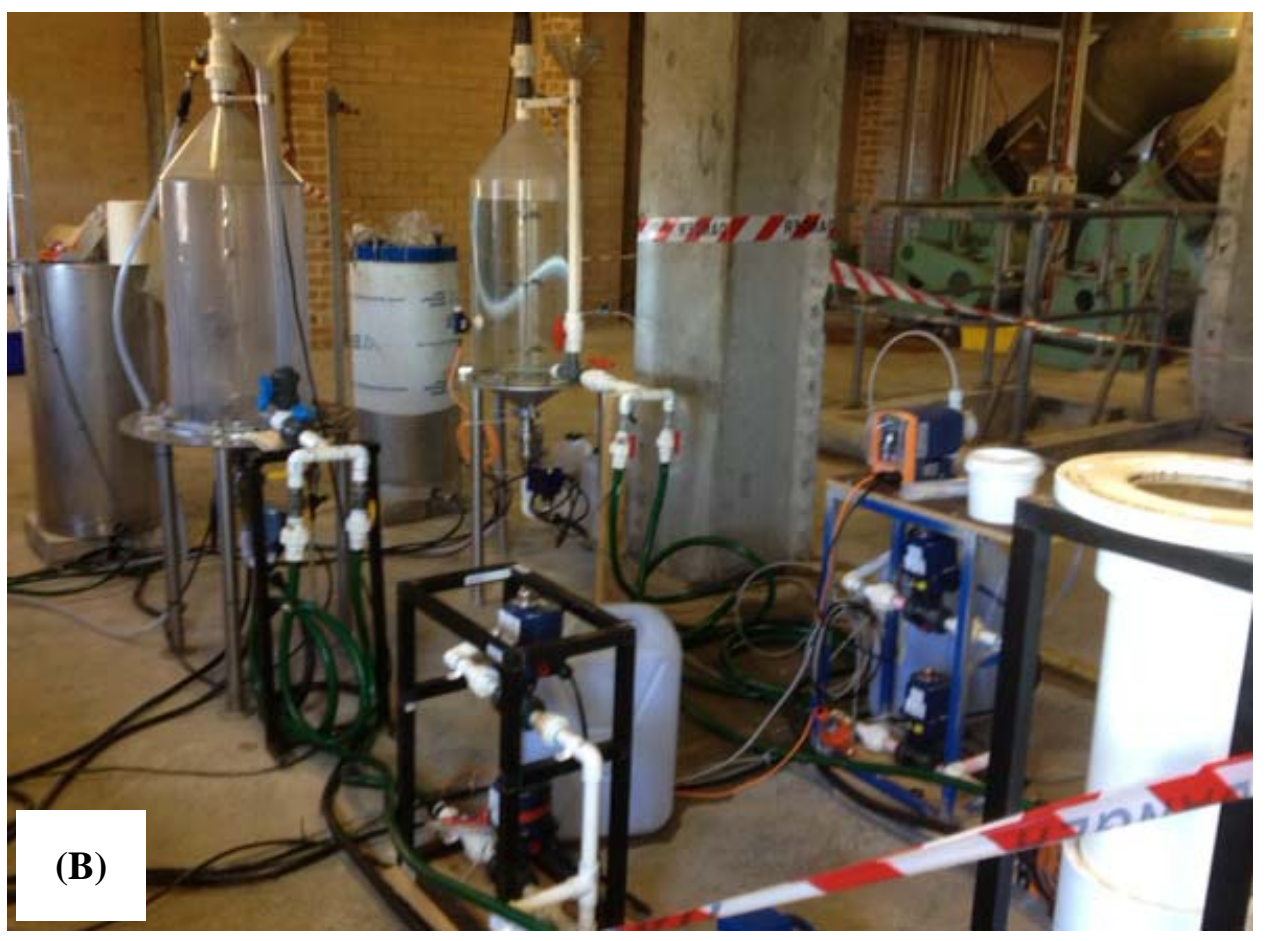

394 Figure 2: (A) Schematic diagram of the pilot anaerobic digester; (B) A picture of the pilot 395 digester. 


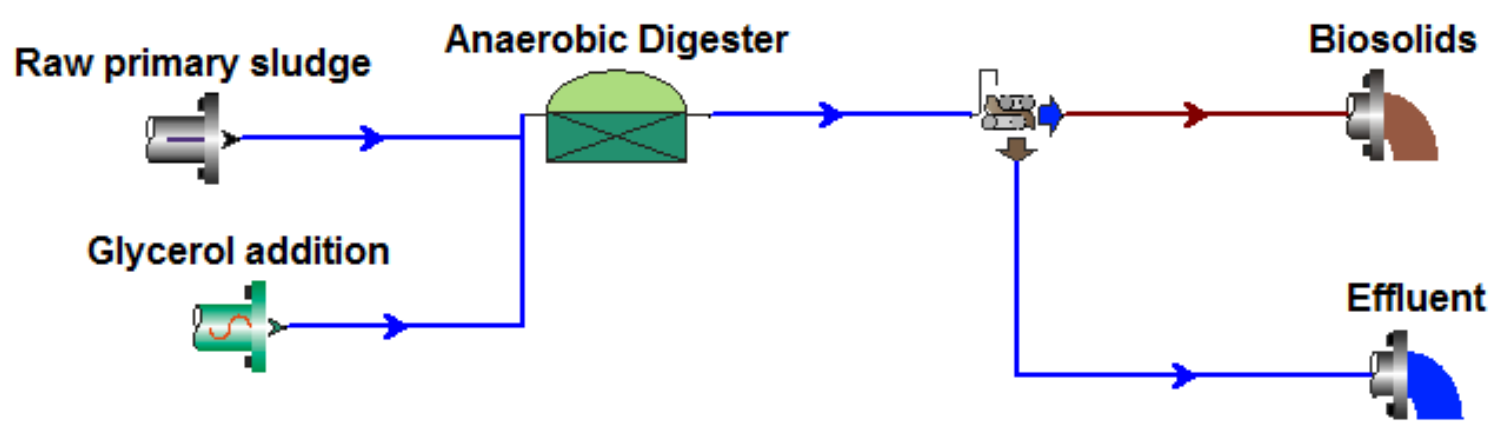

396

397 Figure 3: BioWin configuration of the anaerobic digester model with glycerol addition. 


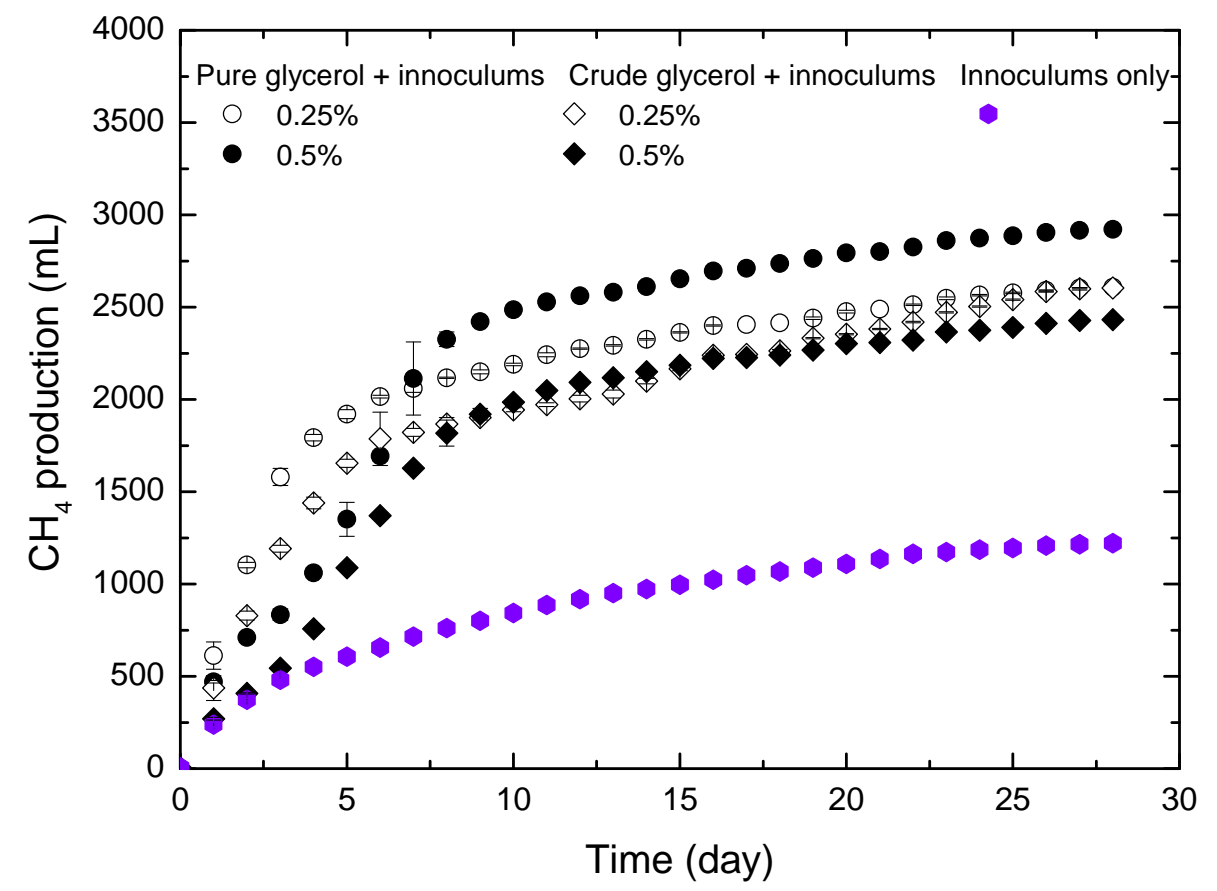

398

399 Figure 4: Methane production as a function of time from glycerol and digested sludge

400 (inoculums) and from only digested sludge. 


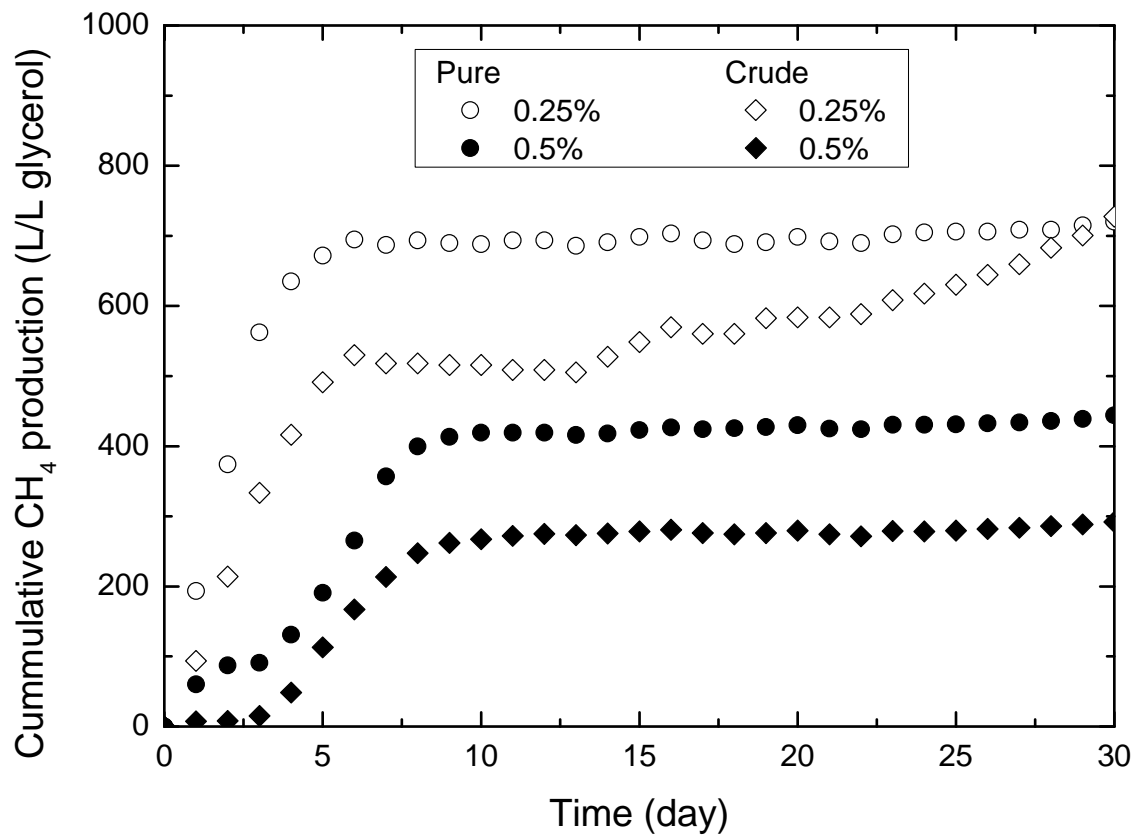

401

402 Figure 5: Methane production from glycerol over time at $0.25 \%$ and $0.5 \%(\mathrm{v} / \mathrm{v})$. 


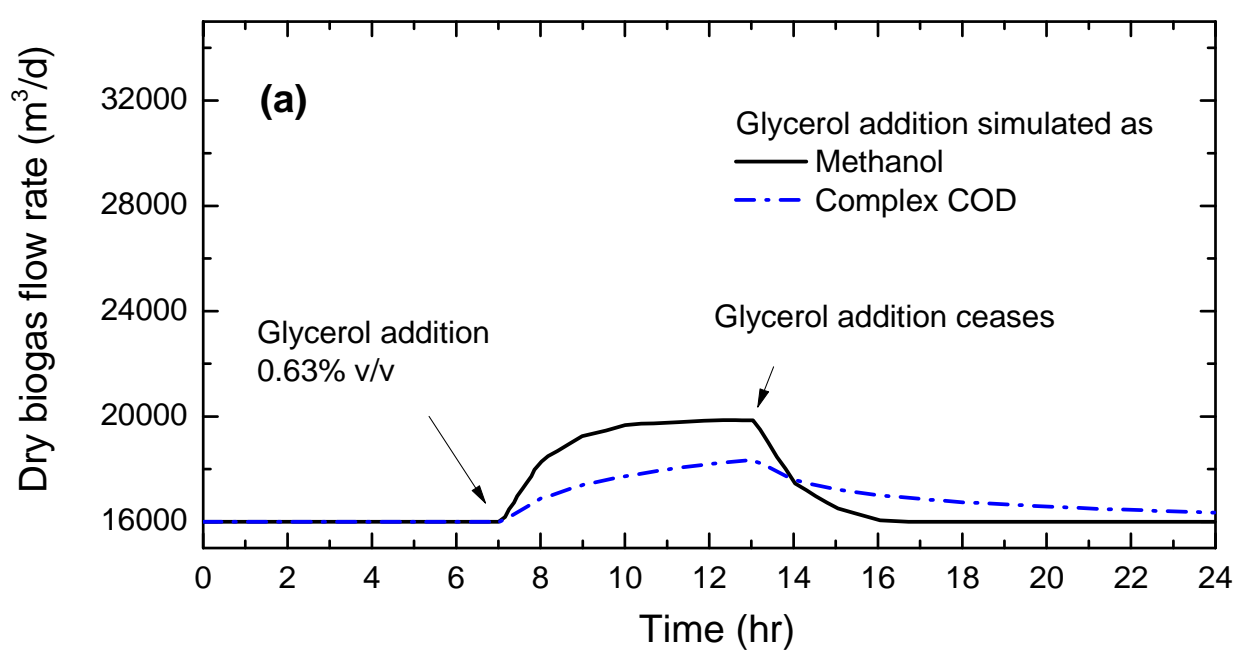

403

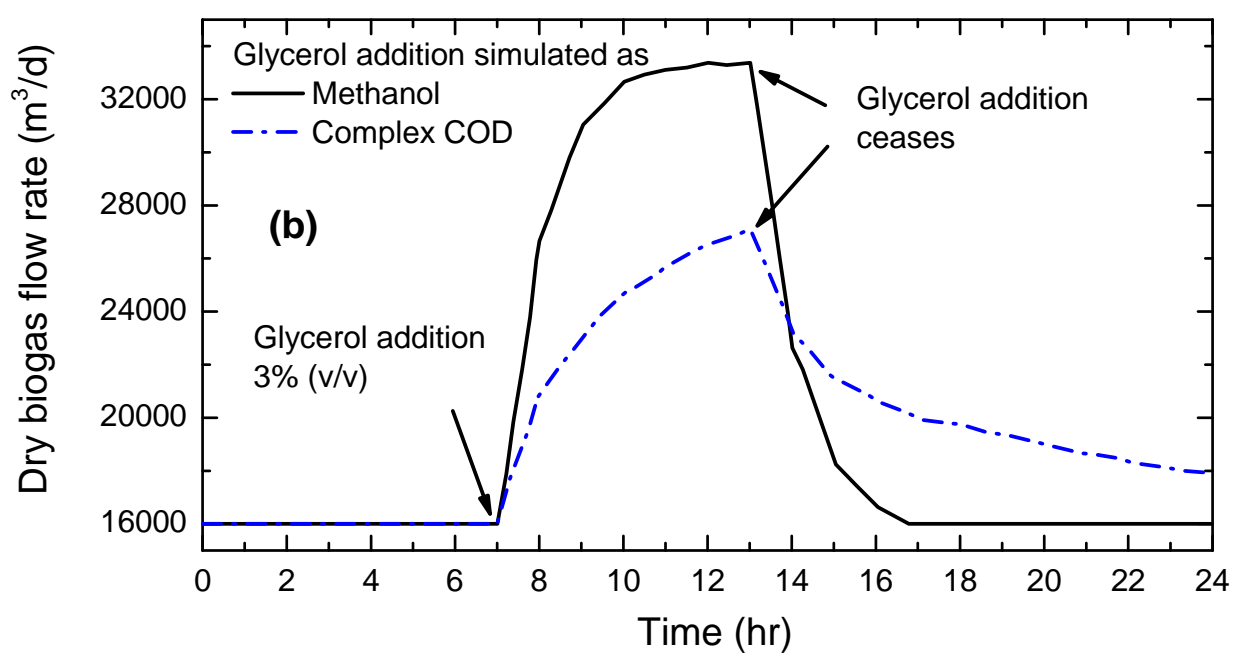

404

405 Figure 6: Simulated biogas flow rate when (a) $0.63 \%$ or (b) $3 \%$ of glycerol was added to the 406 digester from 7 am to $1 \mathrm{pm}$. Glycerol addition was simulated as methanol or readily 407 biodegradable complex substrate. 


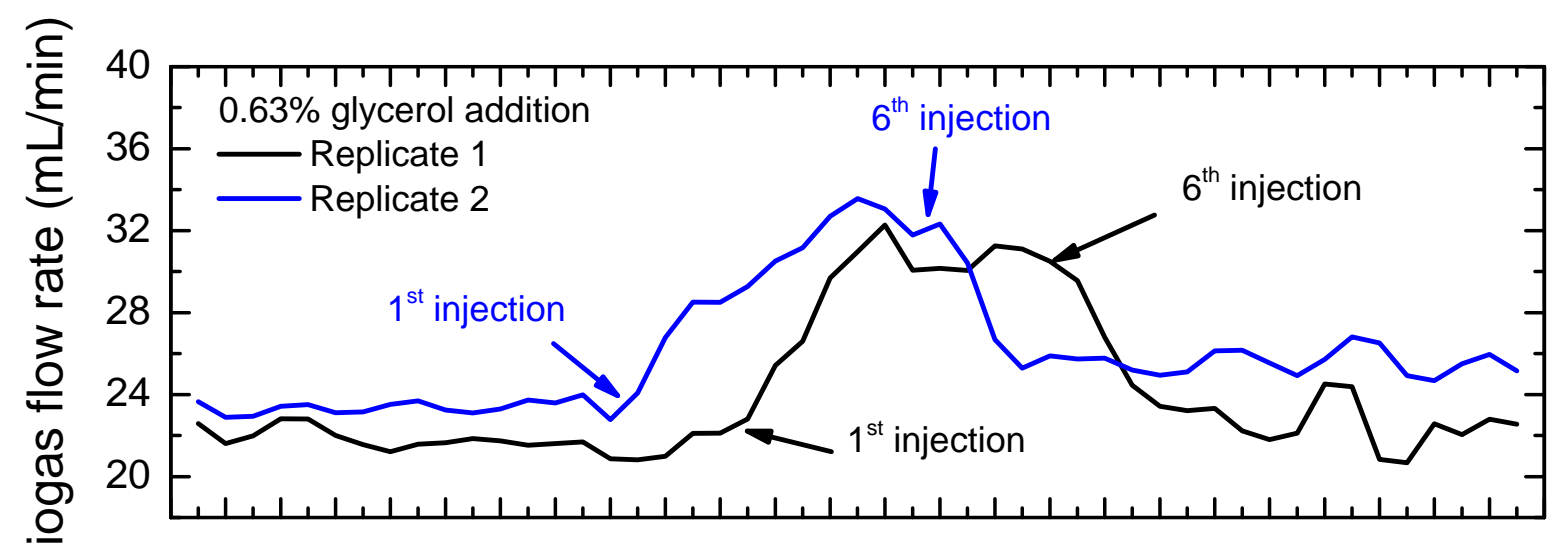

409 Figure 7: Biogas gas flow rate versus time. Crude glycerol was injected to the digester once every hour to obtain (a) $0.63 \%$ and (b) $3 \%$ (v/v) of glycerol in the 410 feed over 6 hours. 